\title{
Introduction to the evolving landscape of the management of glioblastoma
}

We present a special series of Chinese Clinical Oncology addressing the evolving landscape of the management of glioblastoma (GBM). Over the past handful of years, the field has been witness to a tremendous number of advances in our understanding of this disease. Some, such as the incorporation of the molecular characteristics underpinning the biology of the disease have been incorporated into the World Health Organization (WHO) classification system for central nervous system tumors (1). Others such as positive phase 3 results of the trial investigating tumor treating fields (TTFields) for the treatment of newly diagnosed GBM have led to their incorporation into routine clinical care (2). In this Focused Issue we will utilize two approaches to describe this evolving landscape of GBM clinical management. The first will focus on recent advances which have translated directly into shifts in our clinical management and which impact our ongoing and near future clinical investigations. The second will provide descriptive overviews of the management of GBM from clinicians from a range of countries to allow for a clearer understanding of the similarities, discordances, and barriers to optimal care in a geographically specific manner.

Dr. Tadipatri and colleagues provide an overview of the potential for epidemiologic research to provide insight into this rare disease (3). Their work pays particular attention to concurrent medications as well as the molecular characteristics of these tumors. This ties directly to the review by Singer $e t a l$. which carefully considers how the still relatively recent incorporation of molecular characteristics into the formal classification impacts the interpretation of prior (and ongoing) clinical studies and more important how it will be incorporated into the upfront design of future clinical trials (4). Next Drs. Schulte, Berger, Gondi, and colleagues detail how the use of existing therapeutic modalities such as the anti-angiogenic agent bevacizumab (5), cutaneously applied arrays for delivering TTFields (6), and radiation therapy (7), have evolved over the recent past or are actively evolving. This special series should leave the reader with an in depth and practical understanding on the current field of GBM management and investigation.

\section{Acknowledgments}

Funding: None.

\section{Footnote}

Provenance and Peer Review: This article was commissioned by the Editorial Office, Chinese Clinical Oncology for the series "The Evolving Landscape of the Management of Glioblastoma”. The article did not undergo external peer review.

Conflicts of Interest: The author has completed the ICMJE uniform disclosure form (available at https://dx.doi.org/10.21037/cco21-106). The series "The Evolving Landscape of the Management of Glioblastoma" was commissioned by the editorial office without any funding or sponsorship. Dr. RVL served as the unpaid Guest Editor of the series, and serves as an unpaid editorial board member of Chinese Clinical Oncology from Aug 2019 to Jul 2021. Dr. RVL reports research support from NIH P50CA221747, BrainUp 2136, and BMS (drug only); honoraria from serving on a scientific advisory board and speakers' bureau for Novocure; and honoraria for medical editing for EBSCO Publishing and Medlink Neurology and for the creation and presentation of CME board review content for American Physician Institute. The author has no other conflicts of interest to declare.

Ethical Statement: The author is accountable for all aspects of the work in ensuring that questions related to the accuracy or integrity of any part of the work are appropriately investigated and resolved.

Open Access Statement: This is an Open Access article distributed in accordance with the Creative Commons AttributionNonCommercial-NoDerivs 4.0 International License (CC BY-NC-ND 4.0), which permits the non-commercial replication and distribution of the article with the strict proviso that no changes or edits are made and the original work is properly cited (including links to both the formal publication through the relevant DOI and the license). See: https://creativecommons.org/licenses/by-nc$\mathrm{nd} / 4.0 /$. 


\section{References}

1. Louis DN, Perry A, Wesseling P, et al. The 2021 WHO Classification of Tumors of the Central Nervous System: a summary. Neuro Oncol 2021;23:1231-51.

2. Stupp R, Taillibert S, Kanner A, et al. Effect of Tumor-Treating Fields Plus Maintenance Temozolomide vs Maintenance Temozolomide Alone on Survival in Patients With Glioblastoma: A Randomized Clinical Trial. JAMA 2017;318:2306-16.

3. Tadipatri R, Lyon K, Azadi A, et al. A view of the epidemiologic landscape: how population-based studies can lend novel insights regarding the pathophysiology of glioblastoma. Chin Clin Oncol 2020. [Epub ahead of print]. doi: 10.21037/cco.2020.02.07.

4. Singer LS, Feldman AZ, Buerki RA, et al. The impact of the molecular classification of glioblastoma on the interpretation of therapeutic clinical trial results. Chin Clin Oncol 2021. [Epub ahead of print]. doi: 10.21037/cco-21-33.

5. Schulte JD, Aghi MK, Taylor JW. Anti-angiogenic therapies in the management of glioblastoma. Chin Clin Oncol 2020. [Epub ahead of print]. doi: 10.21037/cco.2020.03.06.

6. Berger TR, Wong ET. Tumor treating fields in neuro-oncology: integration of alternating electric fields therapy into promising treatment strategies. Chin Clin Oncol 2020. [Epub ahead of print]. doi: 10.21037/cco.2020.02.04.

7. Gondi V. Dose escalation of radiation for the treatment of glioblastoma. Chinese Clinical Oncology.

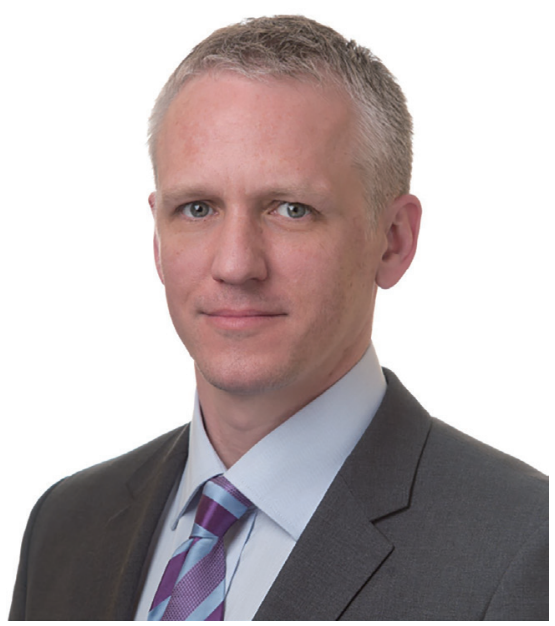

Rimas V. Lukas

Rimas V. Lukas ${ }^{1,2}$

${ }^{1}$ Department of Neurology, Nortbwestern University, Chicago, IL, USA;

${ }^{2}$ Lou \& Jean Malnati Brain Tumor Institute, Cbicago, IL, USA

(Email: rimas.lukas@nm.org)

Submitted Aug 04, 2021; Accepted for publication Aug 13, 2021.

doi: $10.21037 /$ сco-21-106

View this article at: https://dx.doi.org/10.21037/cco-21-106

Cite this article as: Lukas RV. Introduction to the evolving landscape of the management of glioblastoma. Chin Clin Oncol 2021;10(4):34. doi: 10.21037/cco-21-106 